\title{
Behavior of stabilizers in acidified solutions and their effect on the textural, rheological, and sensory properties of cream cheese
}

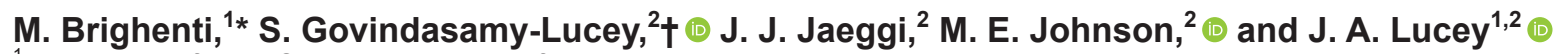 \\ ${ }^{1}$ Department of Food Science, University of Wisconsin, Madison 53706 \\ ${ }^{2}$ Center for Dairy Research, University of Wisconsin, Madison 53706
}

\begin{abstract}
Stabilizers are routinely added during cream cheese manufacture to help prevent syneresis during storage. We investigated how different types of stabilizers affected the texture, rheology, and sensory properties of cream cheese. Cream cheeses were manufactured with $0.33 \%$ xanthan gum (XG), locust bean gum (LBG), guar gum $(\mathrm{GG})$, or a combination $(\mathrm{CBN})$ of these 3 stabilizers ( $0.11 \%$ of each). Rheological properties of solutions of the individual stabilizers and their combination (equal amounts) were also determined under conditions similar to the aqueous phase of cream cheese $(0.6 \%$ gum, $1.8 \% \mathrm{NaCl}$, and $\mathrm{pH} 5$ ). Dynamic small amplitude rheological properties of the cream cheeses were measured during heating from 5 to $80^{\circ} \mathrm{C}$ at the rate of $1^{\circ} \mathrm{C} /$ min and cooling at the same rate (because most cream cheese is hot packed/filled before cooling). Measured rheological parameters included storage modulus $\left(\mathrm{G}^{\prime}\right)$ and loss tangent. Hardness of cream cheeses was determined by texture profile analysis. Quantitative spectrum descriptive sensory analysis was also performed. Distinct differences were observed between the rheological properties of solutions of the individual stabilizers and the CBN containing all the stabilizers. Results showed that CBN solution formed a strong, thermally reversible gel due to synergistic interaction between stabilizers, whereas XG solution formed a weak gel that was not greatly affected by temperature. Solutions of LBG and GG behaved rheologically as entangled polymer solutions. In the high-temperature $\left(>35^{\circ} \mathrm{C}\right)$ region, cream cheeses made with XG and $\mathrm{CBN}$ showed higher $\mathrm{G}^{\prime}$ values compared with other cream cheeses. The $\mathrm{G}^{\prime}$ values were higher for XG- and CBN-stabilized cream cheeses than LBG- and GG-stabilized cream cheeses at several temperature regions during the cooling cycle.
\end{abstract}

Received August 22, 2019.

Accepted November 19, 2019.

*Current address: Cargill European Food Innovation Center, Havenstraat 84, 1800 Vilvoorde, Belgium.

†Corresponding author: rani@cdr.wisc.edu
The CBN-stabilized cream cheeses had higher hardness values than the cream cheeses manufactured with the individual stabilizers. Differences were observed between the sensory attributes of cream cheeses stabilized with CBN and those made with individual stabilizers. At low temperatures, the higher hardness and $\mathrm{G}^{\prime}$ values of CBN-stabilized cream cheeses could be due to synergistic interaction between XG and galactomannans. The higher elasticity of XG-stabilized cream cheeses at high temperatures could be due to its higher thermal stability. This study showed that the stabilizers added during manufacture of cream cheese affected its texture, rheological, and sensory properties.

Key words: texture, rheology, cream cheese, xanthan, galactomannan

\section{INTRODUCTION}

Cream cheese is widely used as an ingredient in products such as flavored spreads and cheesecakes. These applications require cream cheese with specific textural and rheological characteristics. However, information is lacking on how different factors influence these properties. In particular, little information is available about the addition of different types of stabilizers.

During cream cheese manufacture, syneresis is desired when part of the whey is removed to help concentrate the curd (Guinee et al., 1993). However, serum (whey) separation following packaging is considered a major defect and should be minimized (Fox et al., 2000). Fresh acid cheeses (such as cream cheese) have $\mathrm{pH}$ values $(\sim 4.6$ to 5.0$)$ that are near the isoelectric $\mathrm{pH}$ of caseins where the water-holding capacity of these proteins is reduced (Gigante et al., 2006). The primary role of stabilizers in cream cheese is to prevent syneresis during storage (Kosikowski and Mistry, 1997). Addition of stabilizers helps prevents syneresis primarily by increasing the viscosity of the aqueous phase (Bot and Vervoort, 2006). In cream cheese, stabilizers are added to the separated curd (i.e., after part of the whey is removed from the curd; Schulz-Collins and Senge, 2004). Addition of stabilizers before whey removal would 
probably interfere with the expulsion of moisture (i.e., make it harder to remove sufficient moisture during the mechanical separation step). In cream cheese, stabilizers are added to the hot stirred, acidified product that has a high viscosity. During the addition of stabilizers, the cream cheese curd is usually heated $\left(>70^{\circ} \mathrm{C}\right)$ and stirred to enhance the dispersion/hydration of these stabilizers in the aqueous phase of cream cheese. In addition, heating decreases viscosity, allowing the product to be pumped, mixed, and packaged (Lucey, 2002).

The most commonly added stabilizers in cream cheeses manufactured in the United States are xanthan gum (XG), locust bean gum (LBG), or guar gum (GG; Hunt and Maynes, 1997). Often, a combination (CBN) of these 3 gums is used to stabilize cream cheese, although they are also used individually. Xanthan gum is an anionic polysaccharide composed of a $(1,4)-\beta$-Dglucan backbone that is substituted at C-3 on alternate glucose residues by a trisaccharide side chain (Morris, 1995; Pelletier et al., 2001). This side chain consists of $\beta$-D-mannose-(1,4)- $\beta$-D-glucuronic acid-(1,2)- $\beta$-Dmannose with variable levels of noncarbohydrate constituents acetate and pyruvate located in the inner and terminal mannose residues, respectively (Pelletier et al., 2001). Locust bean gum and GG are galactomannans composed of a linear backbone of $(1,4)-\beta$-D-mannose residues substituted with $(1,6)-\alpha$-D-galactose residues. Typical mannose/galactose ratios of LBG and GG are 3.55 and 1.56, respectively (Morris, 1998).

The rheological properties of solutions of these 3 stabilizers, and their mixtures, have been previously studied and results indicated that their rheological behavior greatly differ (Richardson and Ross-Murphy, 1987a,b; Copetti et al., 1997). Galactomannans give viscous solutions (Dea, 1990), whereas XG forms weak gels that, in the presence of salt, exhibit an increased stability to heat and acid conditions (Morris, 1990). Several studies have reported a synergistic interaction between XG and galactomannans (Williams and Phillips, 1995). Most studies indicate that the synergistic interaction between XG and galactomannans is due to direct interactions rather than to any thermodynamic incompatibility (Morris, 1995). However, no molecular model or mechanism is universally accepted for the interaction between XG and galactomannans. When LBG and XG are combined, strong, thermally reversible gels are formed, whereas mixtures of $\mathrm{XG}$ and GG give solutions of high viscosity (Morris, 1998). Little information is available on the properties of mixtures of all 3 (LBG, XG, and GG) of these polysaccharides, or when evaluated under the conditions present in cream cheese (high salt, low $\mathrm{pH}$ ).

Stabilizers can greatly affect the rheology of food systems even when added in small concentrations.
According to Guinee et al. (1993), in fresh acid-curd cheeses, addition of hydrocolloids that bind to the protein network (e.g., k-carrageenan, pectin) interrupt the formation of protein-protein interactions and give softer products. The stabilizers selected for this study, XG, LBG, and GG, do not directly bind (associate) to caseins (Everett and McLeod, 2005). Previous studies have indicated that the addition of nonadsorbing hydrocolloids to skim milk before acidification can introduce changes in the acid-induced gel microstructure (Sanchez et al., 2000; Aichinger et al., 2007) and in the rheology of acid-induced gels (Aichinger et al., 2007). In cream cheese, stabilizers are added to the fermented product.

The objective of this study was to determine how the stabilizers: XG, LBG, GG, and CBN affect the rheological, textural, functionality, and sensory properties of cream cheese. The rheological properties of solutions of these stabilizers and of their equal combination were also characterized and compared with the rheological behavior of cream cheeses stabilized with these hydrocolloids.

\section{MATERIALS AND METHODS}

\section{Rheological Properties of Solutions of Stabilizers}

The stabilizers used in this study were XG (Satiaxane CX90 DF, Cargill Inc., Minneapolis, MN), LBG (Viscogum BE, Cargill Inc.), and GG (Viscogum 202, Cargill Inc.).

Rheological properties of the stabilizer solutions were determined by a controlled-stress rheometer Paar Physica UDS 200 (Physica Messtechnik, Stuttgart, Germany). A cup and bob measuring geometry (Z3 DIN) consisting of 2 coaxial cylinders with inner and outer diameters of 25.0 and $27.5 \mathrm{~mm}$, respectively, was used. Solutions of XG, LBG, GG, and CBN were prepared under conditions similar to those of the aqueous phase of cream cheese $(0.6 \%$ stabilizers, $1.8 \% \mathrm{NaCl}$, and $\mathrm{pH}$ 5.0). Stabilizers, together with the salt, were dissolved in deionized water at room temperature. Sodium azide $(0.02 \%)$ was added to prevent bacterial growth and the $\mathrm{pH}$ was adjusted to 5.0 with lactic acid. Solutions were stored at $5^{\circ} \mathrm{C}$ until they were analyzed.

Solutions of stabilizers were first heated to $80^{\circ} \mathrm{C}$ for $30 \mathrm{~min}$ in a water bath while being vigorously stirred (for rehydration purposes). Solutions were transferred to the cup system of the rheometer while they were still hot, where they were immediately cooled to $5^{\circ} \mathrm{C}$ and maintained at that temperature for $2 \mathrm{~h}$ before analysis. Vegetable oil was added to the surface of the sample in the rheometer to prevent evaporation. Frequency sweep tests were performed on the model stabilizer solutions 
at a temperature of $5^{\circ} \mathrm{C}$ to determine the effect of the time-scale of deformation on their rheological properties. This was also performed to understand the nature of the system, that is, was the solution a gel? A strain of $1 \%$ was applied at frequencies that ranged from 0.001 to $1 \mathrm{~Hz}$.

The effect of temperature on the behavior of the model stabilizer solutions was evaluated by temperature sweep tests. This was done to understand how these stabilizers might behave during the hot filling and cooling operations of cream cheese manufacture. Solutions were heated from 5 to $80^{\circ} \mathrm{C}$ and subsequently cooled from 80 to $5^{\circ} \mathrm{C}$ at a heating rate of $1^{\circ} \mathrm{C} / \mathrm{min}$. A frequency of $0.1 \mathrm{~Hz}$ and a strain of $1 \%$ were used while the storage modulus $\left(\mathbf{G}^{\prime}\right)$ and loss tangent $(\mathbf{L T})$ were measured.

Large deformation properties of the solutions were also determined by applying a single, constant shear rate $\left(0.232 \mathrm{~s}^{-1}\right)$ up to a yield point, which was defined as the point when the shear stress values started to decrease (Lucey et al., 1997). Parameters measured were yield stress $\left(\boldsymbol{\sigma}_{\text {yield }}\right)$ and yield strain at yielding $\left(\gamma_{\text {yield }}\right)$.

\section{Textural Properties of Solutions of Stabilizers}

Solutions of stabilizers were first heated to $80^{\circ} \mathrm{C}$ for $30 \mathrm{~min}$ in a water bath while being vigorously stirred. Solutions were transferred to $250-\mathrm{mL}$ plastic beakers and placed in the refrigerator $\left(\sim 4^{\circ} \mathrm{C}\right)$ for $1 \mathrm{~d}$ before analysis.

A penetration test was performed using a TA.TXT2 Texture Analyzer (Texture Technologies Corp., Scarsdale, NY) equipped with a 5 -kg cell and a temperaturecontrolled chamber (Temperature Applied Sciences Ltd., West Sussex, UK) maintained at $4^{\circ} \mathrm{C}$. The penetration test was carried out on the samples when they were in the chamber. A cylindrical stainless steel probe with a diameter of $45 \mathrm{~mm}$ (TA-94) was introduced 30 $\mathrm{mm}$ into the gels at a speed of $1 \mathrm{~mm} / \mathrm{s}$. The parameter measured was hardness, which was defined as the maximum force during penetration.

\section{Cream Cheese Manufacture}

Two licensed Wisconsin cheese makers manufactured 3 replicate trials of cream cheeses at the University of Wisconsin-Madison Dairy Plant as described by Brighenti et al. (2018). On each cheesemaking day, 4 square-shaped, jacketed stainless-steel open cheese vats (Stoelting LV60, Kiel, WI), with a maximum capacity of $272 \mathrm{~kg}$ of milk, were used to manufacture the cream cheeses on 3 separate days over a period of 3 mo. Cream cheese mix was prepared by blending whole milk and cream to obtain a fat content of $11.7 \pm 0.7 \%$.
The standardized cream cheese mix was pasteurized at $77^{\circ} \mathrm{C}$ for $19 \mathrm{~s}$ and then homogenized (Gaulin Type 800E, W. M. Sprinkman Corp., Franksville, WI) in 2 stages (17.5 and $5 \mathrm{MPa}$ ). Each vat was filled with 136 $\mathrm{kg}$ of the cream mix. The mix was added to 4 different cheese vats where it was inoculated with a mesophilic bulk culture (0.1\%, wt/wt, Flav 1; Cargill Texturizing Solutions, Waukesha, WI) containing Lactococcus lactis ssp. lactis, Lactococcus lactis ssp. cremoris, Lactococcus lactis ssp. diacetylactis, and Leuconostoc mesenteroides ssp. cremoris. Each cheese vat was incubated at $23^{\circ} \mathrm{C}$ until the $\mathrm{pH}$ reached $\sim 4.70$.- Each cultured mix was then stirred and heated until a temperature of $80^{\circ} \mathrm{C}$ was reached $(\sim 35 \mathrm{~min})$. The hot mixtures were then pumped individually to a cream cheese centrifugal separator (Sharples centrifuge, model DS-2, Penwalt Corporation/Sharples Stokes division, Warminster, PA) where part of their whey was removed from the acid curds. After separation, approximately $36 \mathrm{~kg}$ of cream cheese was obtained and the curd was pumped into a jacketed swept surface holding tank (model CBP 30, Scherping Systems, Winsted, MN). Curd was constantly agitated for $\sim 30$ min while the temperature was held at $\sim 76^{\circ} \mathrm{C}$. Salt $(1 \%$, wt/wt) and stabilizers $(0.33 \%$, wt $/ w t)$ were added during this period. Each cream cheese was stabilized with a different stabilizer: $\mathrm{XG}, \mathrm{LBG}, \mathrm{GG}$, or CBN of these 3 stabilizers $(0.11 \%$, wt/wt of each). The moisture content of each curd was checked by a rapid microwave test (CEM Smart System 5 Moisture/Solids Analyzer, CEM Corporation, Matthews, NC), and if necessary, moisture was adjusted to $\sim 55 \%$ by the addition of separated acid whey. After $\sim 30$ min of mixing, each curd was pumped into a cream cheese homogenizer (Gaulin Type 100DJ F3 8SS, W. M. Sprinkman Corp., Franksville, WI) where it was homogenized at $1.7 \mathrm{MPa}$ for both stages. The curds were then hot-packaged at a temperature of $\sim 75^{\circ} \mathrm{C}$ into five 2.2-kg cylindrical plastic containers (diameter: $14 \mathrm{~cm}$, height: $19 \mathrm{~cm}$ ) for each treatment. Samples were placed in a refrigerated room for storage at $\sim 4^{\circ} \mathrm{C}$.

\section{Compositional Analyses}

Cream cheese mixes were analyzed for TS (IDF, 2010), fat by Mojonnier (AOAC International, 2000), total protein (total percentage $\mathrm{N} \times 6.35$ ) by Kjeldahl (AOAC International, 2000), true protein, casein (Marshall, 1992), and total Ca using inductively coupled plasma emission spectroscopy (Govindasamy-Lucey et al., 2007). Lactose was determined by an enzymatic method (AOAC International, 2000; Boehringer Mannheim Biochemicals, Mannheim, Germany).

Cream cheeses were analyzed 1 wk after manufacture for moisture (IDF, 2004), fat (AOAC International, 
2000), total protein by Kjeldahl (AOAC International, 2000), salt (Corning Salt Analyzer, Corning Glass Works, Medfield, MA; Marshall, 1992), total Ca using inductively coupled plasma emission spectroscopy (Govindasamy-Lucey et al., 2007), and lactose and lactic acid (AOAC International, 2000; Boehringer Mannheim Biochemicals). The $\mathrm{pH}$ values were determined by insertion of a $\mathrm{pH}$ probe $(\mathrm{pH}$ meter $420 \mathrm{~A}$, Orion Research, Beverley, MA) into the cheeses.

\section{Preparation of Cream Cheese Samples for Rheological and Textural Analyses}

Samples for rheological tests, were prepared as described by Brighenti et al. (2018). Fifty-milliliter syringes (Henke-Sass Wolf GmbH, Tuttlingen, Germany) with an internal diameter of $29 \mathrm{~mm}$ were used, whereas for texture analysis, the syringes (Becton, Dickinson and Company, Franklin Lakes, NJ) had a volume of 20 $\mathrm{mL}$ and an internal diameter of $16 \mathrm{~mm}$. The syringes had their nozzles removed (cut off) and these syringes were filled with cream cheese during the manufacturing process at the packaging stage (i.e., while it was still hot, and therefore liquid/viscous). Three syringes filled with cream cheese were stored inside the middle of the $2.2-\mathrm{kg}$ plastic containers assigned for rheological analyses. Likewise, 3 syringes allocated for textural analyses were filled with cream cheeses and stored in separate containers assigned for textural analyses. The containers were filled with cream cheese and this allowed the syringes to cool along with the rest of the product in a cold room at $4^{\circ} \mathrm{C}$. This was done to have a similar cooling profile as the rest of the cream cheese samples. The cream cheeses in these containers were not used for any other analyses. After $4 \mathrm{wk}$ of storage at $4^{\circ} \mathrm{C}$, the samples were extruded out of the syringes as a cylinder using the plunger of the syringe. Samples were cut to the desired thickness using a cheese slicer (samples were maintained at $\sim 4^{\circ} \mathrm{C}$ ). For rheological tests, samples had a thickness of 2 to $3 \mathrm{~mm}$ and a diameter of 29 $\mathrm{mm}$, whereas samples for texture analysis had diameter and height of $\sim 16 \mathrm{~mm}$. Samples were stored at $4^{\circ} \mathrm{C}$ for at least $2 \mathrm{~h}$ to allow for structure recovery from the preparation steps before they were analyzed for their rheological or textural properties.

\section{Rheological and Textural Properties of Cream Cheeses}

The rheological properties of cream cheeses were determined by the dynamic small-amplitude oscillatory rheology technique as described by Brighenti et al. (2018). A controlled-stress rheometer (Paar Physica
UDS 200, Anton Paar, Ashland, VA) with a 25-mm serrated probe and a parallel plate geometry was used. A frequency of $0.1 \mathrm{~Hz}$ and a strain of $0.05 \%$ were used (strain sweep tests indicated that this was within the linear viscoelastic region; results not shown). Samples were heated from 5 to $80^{\circ} \mathrm{C}$ and immediately cooled from 80 to $5^{\circ} \mathrm{C}$ at a heating rate of $1^{\circ} \mathrm{C} / \mathrm{min}$. Samples were maintained at $5^{\circ} \mathrm{C}$ for $30 \mathrm{~min}$. All analyses were carried out in triplicate. The parameters measured were $\mathrm{G}^{\prime}$ and $\mathrm{LT}$.

\section{Textural Properties of Cream Cheeses}

Texture profile analysis was performed using the TA.XT2 Texture Analyzer equipped with the 5-kg cell and the temperature-controlled chamber maintained at $4^{\circ} \mathrm{C}$. Analyses were carried out at $4^{\circ} \mathrm{C}$ by placing the samples in the chamber. Cylindrical samples were compressed twice with a 50-mm aluminum cylindrical probe at a speed of $1 \mathrm{~mm} / \mathrm{s}$ and compressed to a strain of $60 \%$. All tests were replicated at least 5 times. The parameter measured was hardness, which was defined as the maximum force during the first compression.

\section{Sensory Textural Properties of Cream Cheeses}

A trained sensory panel consisting of at least 8 panelists (usually 8 to 12 ) used quantitative spectrum descriptive analysis (Meilgaard et al., 1999) to evaluate the following textural attributes of cream cheese: firmness, stickiness, cohesiveness of mass, gumminess, difficulty to dissolve, particle size, and difficulty to spread. The training of the panel, the choice of the textural attributes and the references used to quantify their intensity as well as the preparation of samples and their evaluation were previously described (Brighenti et al., 2008, 2018). All sensory panels were conducted in duplicate on 2 different days.

\section{Experimental Design and Statistical Analysis}

Three replicate cheesemaking trials were carried out; in each trial, 4 cream cheeses were manufactured. Each cream cheese was stabilized with a different stabilizer: $\mathrm{XG}, \mathrm{LBG}, \mathrm{GG}$, or CBN of these 3 stabilizers $(0.11 \%$, $\mathrm{wt} / \mathrm{wt}$ of each). The effects of type of stabilizer on the rheological, textural, and sensory properties of cream cheeses were determined by using PROC Mixed for repeated measurement in SAS software (version 8.02, SAS Institute Inc., Cary, NC). When treatment effect was significant $(P \leq 0.05)$, the difference between means was analyzed using Duncan's method for multiple comparisons of means. 


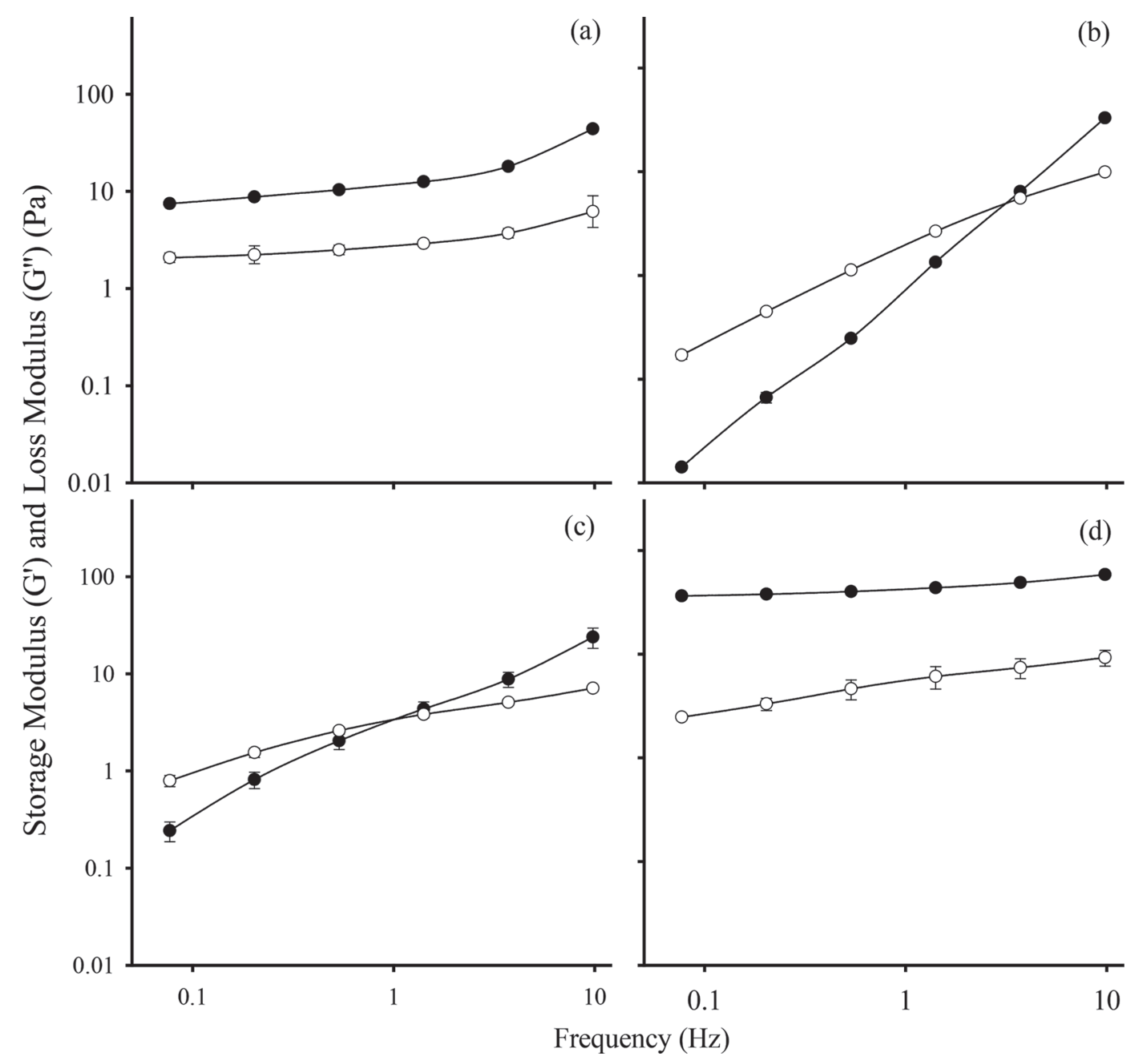

Figure 1. Storage modulus $\left(\mathrm{G}^{\prime}\right)$ values $(\bullet)$ and loss modulus $\left(\mathrm{G}^{\prime \prime}\right)$ values $(\bigcirc)$ of solutions containing $0.6 \%$ stabilizers, $1.8 \% \mathrm{NaCl}$, and $\mathrm{pH}$ 5.0 for xanthan gum (a), locust bean gum (b), guar gum (c), or a combination of all 3 stabilizers $(0.2 \%$ each of xanthan, locust bean gum, and guar gum; d) as a function of frequency. Samples were tested at $5^{\circ} \mathrm{C}$. Values are means of 3 replicates and error bars represent SD of the mean.

\section{RESULTS AND DISCUSSION}

\section{Rheological Properties of Solutions of Stabilizers}

Clear differences were observed in the frequency sweep profiles for the various stabilizer solutions at the concentration, salt level, and $\mathrm{pH}$ values selected for this study (Figure 1). Solutions of XG (Figure 1a) and CBN (Figure 1d) had higher values of $\mathrm{G}^{\prime}$ than $\mathrm{G}^{\prime \prime}$ at all frequencies compared with solutions of LBG (Figure 1b) or GG (Figure 1c). The CBN solution had higher $\mathrm{G}^{\prime}$ values (Figure 1d) and greater frequency-independence than those of the XG solution (Figure 1a). In the case of the solutions of galactomannans, values of $\mathrm{G}^{\prime}$ were lower than those of $G^{\prime \prime}$ until crossover frequencies were exceeded $\left(\mathrm{G}^{\prime}=\mathrm{G}^{\prime \prime}\right.$ at $\sim 4 \mathrm{~Hz}$ for $\mathrm{LBG}$ and at $\sim 1 \mathrm{~Hz}$ for GG; Figures $1 \mathrm{~b}$ and 1c, respectively). At frequencies higher than the crossover frequencies, $G^{\prime}$ values were higher than those of $\mathrm{G}^{\prime \prime}$ for solutions of LBG and GG. These profiles indicated that solutions XG and CBN formed gels, whereas LBG and GG were entangled solutions (not gels; Pai and Khan, 2002).

During the heating cycles in temperature sweep experiments, the $\mathrm{CBN}$ solutions had the highest $\mathrm{G}^{\prime}$ values at temperatures below $\sim 35^{\circ} \mathrm{C}$ (Figure 2a). During heating, the $\mathrm{G}^{\prime}$ values of $\mathrm{CBN}$ solutions decreased up to $60^{\circ} \mathrm{C}$; thereafter the $G^{\prime}$ values hardly changed (Figure 2a). Storage modulus values of XG solutions also decreased slightly with increasing temperature. Storage modulus values of GG and LBG were $\ll 1 \mathrm{~Pa}$ at all temperatures during the heating and cooling cycles (Figure 2). During the cooling cycle (Figure $2 \mathrm{~b}$ ), the $\mathrm{G}^{\prime}$ values of $\mathrm{CBN}$ and $\mathrm{XG}$ increased as the temperature decreased. The $\mathrm{G}^{\prime}$ values of $\mathrm{CBN}$ and $\mathrm{XG}$ solutions after the heating 


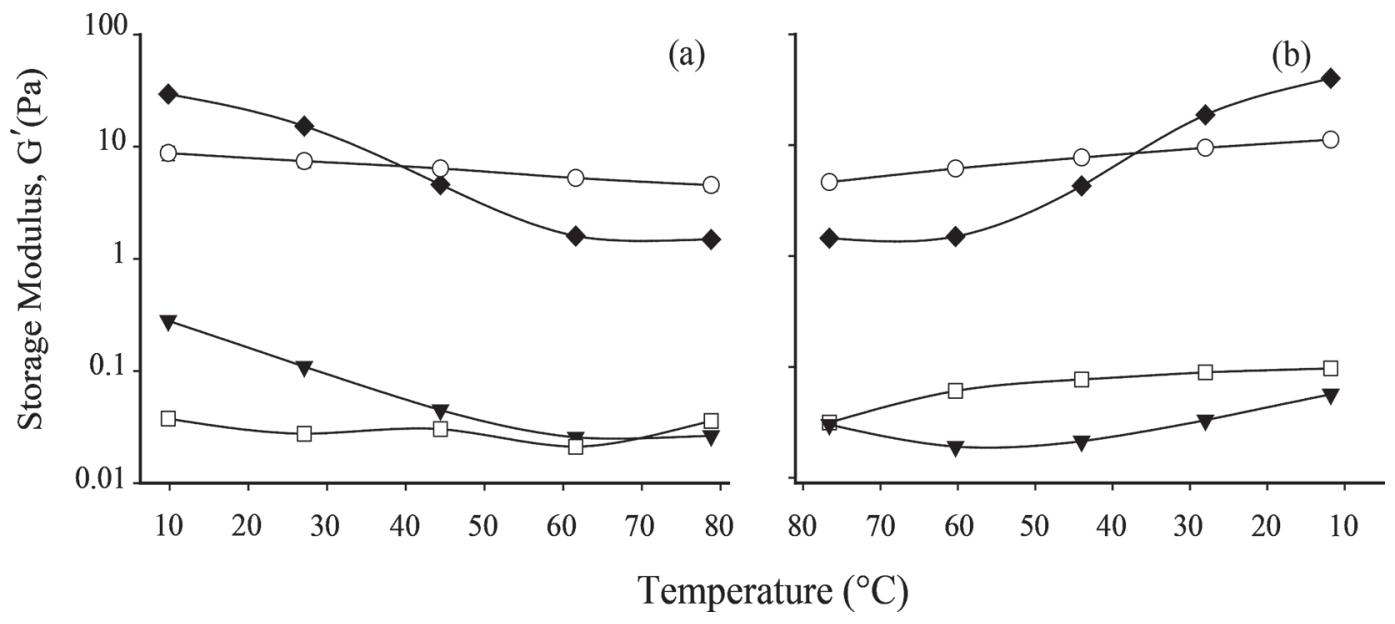

Figure 2. Storage modulus values of solutions of $0.6 \%$ stabilizers, $1.8 \% \mathrm{NaCl}$, and pH 5.0 for xanthan gum $(\bigcirc)$, locust bean gum $(\square)$, guar gum $(\mathbf{v})$, and a combination of all 3 stabilizers (xanthan, locust bean gum, and guar gum; $\$$ ) during heating (a) and cooling (b). Heating was from 5 to $80^{\circ} \mathrm{C}$ and cooling from 80 to $5^{\circ} \mathrm{C}$ at $1^{\circ} \mathrm{C} / \mathrm{min}$. Values are means of 3 replicates and error bars represent $\mathrm{SD}$ of the mean.

and cooling cycles were similar to those obtained before heating. The LT values of the CBN and XG solutions were $<0.4$ at all temperatures studied during the heating and cooling cycles (Figures $3 \mathrm{a}$ and $\mathrm{b}$ ). During the heating cycle, the CBN solution showed a maximum value $(\sim 0.28)$ at approximately $56^{\circ} \mathrm{C}$, and during the cooling cycle, a maximum $(\sim 0.24)$ was observed at approximately $50^{\circ} \mathrm{C}$. The LT values of $\mathrm{XG}$ solution were higher than those observed in the CBN solution at all temperatures; however, XG solution showed no clear LT peak in this temperature range. For LBG and GG solutions, $\mathrm{G}^{\prime \prime}$ values were higher than $\mathrm{G}^{\prime}$ values at all temperatures and therefore their LT values were $>1$.

The CBN solution formed gels with highest $\sigma_{\text {yield }}$ and $\gamma_{\text {yield }}$ values (Table 1 ). Gels with lower $\sigma_{\text {yield }}$ and $\gamma_{\text {yield }}$ values were obtained for XG, whereas solutions of LBG and GG did not exhibit a detectable yield point under the conditions of this experiment. In addition, the gels formed by CBN solutions had the highest hardness, with values $\sim 19.6 \mathrm{~N}$, whereas the weaker gels formed in XG solutions had hardness values $\sim 0.98 \mathrm{~N}$ and solutions of GG and LBG had values $\sim 0.49 \mathrm{~N}$ (results not shown).

In the case of XG solutions, results from the frequency sweep test (i.e., $G^{\prime}>G^{\prime \prime}$ at all frequencies; Figure 1a) and the presence of a yield stress (Table 1) are both indicators of the presence of a gel. The behavior of XG during the heating and cooling cycles of the temperature sweep test indicated that the structure present in this solution was relatively stable over the temperature range from 5 to $80^{\circ} \mathrm{C}$. The decrease in the $\mathrm{G}^{\prime}$ values with an increase in temperature was not very pro-

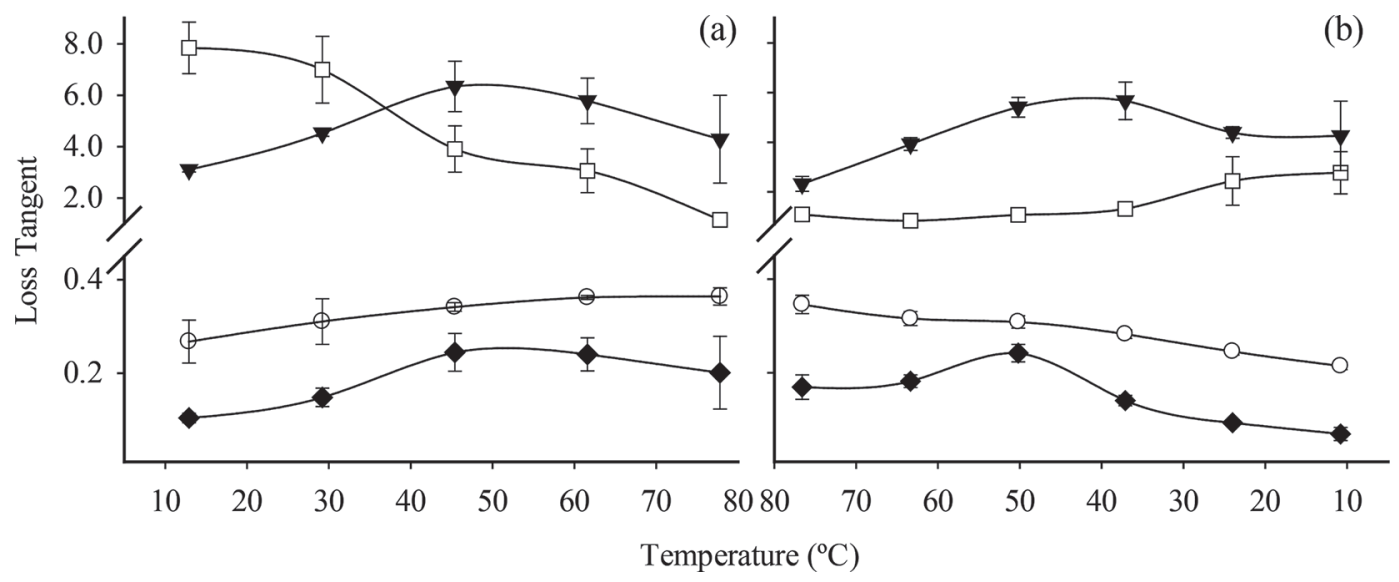

Figure 3. Loss tangent values of solutions of $0.6 \%$ stabilizers, $1.8 \% \mathrm{NaCl}$, and pH 5.0 for xanthan gum $(\bigcirc)$, locust bean gum ( $\square$ ), guar gum $(\mathbf{v})$, and a combination of all 3 stabilizers (xanthan, locust bean gum, and guar gum; ) during heating (a) and cooling (b). Heating was from 5 to $80^{\circ} \mathrm{C}$ and cooling from 80 to $5^{\circ} \mathrm{C}$ at $1^{\circ} \mathrm{C} / \mathrm{min}$. Values are means of 3 replicates and error bars represent $\mathrm{SD}$ of the mean. 
Table 1. Large deformation properties ${ }^{1}$ of the different stabilizer solutions

\begin{tabular}{lcc}
\hline Gum solution & Yield stress $^{2}(\mathrm{~Pa})$ & Yield strain $^{2}$ \\
\hline Combination & $188.5 \pm 17.7$ & $1.4 \pm 0.1$ \\
Xanthan & $9.6 \pm 0.7$ & $0.9 \pm 0.0$ \\
Guar & $\mathrm{NY}^{3}$ & $\mathrm{NY}$ \\
Locust bean & $\mathrm{NY}$ & $\mathrm{NY}$ \\
\hline
\end{tabular}

${ }^{1}$ Mean and SD of triplicate experiments.

${ }^{2}$ Yield was defined as the point when the shear stress started to decrease when gels were subjected to a constant shear rate of $\sim 0.232 \mathrm{~s}^{-1}$.

${ }^{3} \mathrm{NY}=$ no yield point observed under the conditions of the experiment.

nounced (Figure 2a), and little change was observed in the $\mathrm{LT}$ values as they remained $<1$ at all temperatures, indicating the presence of a solid-like gel structure in the material (Figures 3a and b). The behavior of XG in solution has been frequently described as resembling that of a weak gel (Morris, 1998). According to Rochefort and Middleman (1987) at the concentration used in this study $(0.6 \%)$, the rheological behavior of $\mathrm{XG}$ is mainly determined by intermolecular interactions. At low temperatures and low ionic strength, XG molecules are in a partially ordered form that is extended due to electrostatic repulsion from the side chains (Rochefort and Middleman, 1987). These highly extended molecules associate through non-covalent interactions to form weakly structured materials (Khouryieh et al., 2007). When heated above $40^{\circ} \mathrm{C}$, the partially ordered molecules become coil-like structures; molecules are then dissociated and the structure of the solution is disrupted (Rochefort and Middleman, 1987). However, when the ionic strength of the solution is increased, the charges from the side chains of XG are screened and these side chains fold onto the backbone, forming a helical configuration (Muller et al., 1986). An increase in the ionic strength of a XG solution results in an increase in structure (higher $\mathrm{G}^{\prime}$ and $\mathrm{G}^{\prime \prime}$ values) as the ordered molecules of XG align and associate more easily through non-covalent interactions. Also, at high ionic strengths, the transition from the ordered configuration to the coil-like structure occurs at higher temperatures (Kitamura et al., 1990). In the XG solution prepared for our study, the ionic strength was high $(\sim 1.6 \% \mathrm{NaCl})$ to mimic the aqueous phase of cream cheese, which could explain the high thermal stability of the structure present in the XG solution.

In the case of the galactomannans, LBG and GG, the values of $G^{\prime}$ and $G^{\prime \prime}$ obtained from the frequency sweep tests (Figures $1 \mathrm{~b}$ and $\mathrm{c}$ ) indicated that they behaved as weakly viscous or entangled solutions (Daubert and Foegeding, 1998). Robinson et al. (1982) and Sittikijyothin et al. (2005) found that at room temperature and at concentrations similar to those used in this study, solutions of GG and LBG behaved as weakly viscous solutions (i.e., $\mathrm{G}^{\prime \prime}$ values were higher than $\mathrm{G}^{\prime}$ at all frequencies). Crossover frequencies were only present at higher concentrations $(\sim 3 \%)$ for these galactomannans (Robinson et al., 1982; Sittikijyothin et al., 2005). A crossover was observed in our study and this difference could be due to the lower temperature used in our study $\left(5^{\circ} \mathrm{C}\right)$, which favors the formation of some non-covalent interactions (i.e., hydrogen bonds) between molecules. The large deformation tests for GG and LBG solutions indicated that no yield point was observed (Table 1), under the conditions selected for this experiment, which is in agreement with the suggestion of an entangled polymer solution (Figure 1). The low $\mathrm{G}^{\prime}$ values and LT values $>1$ at all temperatures during the heating and cooling cycles also indicate the presence of viscous solutions (not gels) under these conditions (Figures 2 and 3 ).

For the CBN solution, the characteristic pattern obtained from the frequency sweep test $\left(\mathrm{G}^{\prime}>\mathrm{G}^{\prime \prime}\right.$ at all frequencies; Figure 1d) and the presence of a yield stress when subjected to the large deformation test (Table 1), indicated the presence of a gel network. The gel formed in the CBN solution was stiffer than those formed by $\mathrm{XG}$, as evidenced by the higher values for $\mathrm{G}^{\prime}$ and $\mathrm{G}^{\prime \prime}$, the higher frequency independence obtained from the frequency sweep test (Figure 1d), the higher values of $\sigma_{\text {yield }}$ and $\gamma_{\text {yield }}$ obtained from the large deformation test (Table 1), and the higher hardness obtained from the penetration test (results not shown). From the temperature sweep tests, the CBN gel showed the highest $\mathrm{G}^{\prime}$ values at low temperatures $\left(<25^{\circ} \mathrm{C}\right)$; these values decreased steeply up to $\sim 60^{\circ} \mathrm{C}$ during the heating phase from 5 to $80^{\circ} \mathrm{C}$ (Figure 2a). During cooling, the increase in $G^{\prime}$ values with a decrease in temperature, and the recovery of the structure after the heating and cooling cycles, indicated that the CBN gel was thermally reversible. The maxima in the $\mathrm{LT}$ values during heating occurred at $\sim 56^{\circ} \mathrm{C}$ and cooling at $\sim 50^{\circ} \mathrm{C}$ indicated that transitions in the structure of the gel occurred at these temperatures. However, the LT values of the CBN did not exceed 1.0 at any temperature during the heating or cooling cycle (Figures 3a and b), which indicated the presence of a more solid-like than liquid-like structure even after the gel was weakened by heating.

At $5^{\circ} \mathrm{C}$, the $\mathrm{CBN}$ system formed a gel with a stiffer structure compared with those of the individual stabilizer solutions. This indicates a synergistic interaction between XG and galactomannans, which has been previously reported by many authors (e.g., Williams and Phillips, 1995). Xanthan forms thermally reversible gels with LBG; in mixtures with GG, viscosity is increased (Morris, 1998). Although the structure of the CBN gel greatly weakened at temperatures $>60^{\circ} \mathrm{C}$, some structure was still present as evidenced by the LT values 
$<1$. Previous studies (Fernandes, 1995) also observed values of LT $<1$ in gels formed between LBG and XG when heated up to $70^{\circ} \mathrm{C}$, which they attributed to the individual contributions of XG and LBG molecules to the structure of the system.

\section{Compositional Analyses of Cream Cheese Mixes and Cream Cheeses}

The average composition of the standardized cream mixes used to manufacture the cream cheeses are 19.6 $\pm 0.7 \%$ TS, $11.7 \pm 0.7 \%$ fat, $2.7 \pm 0.1 \%$ true protein, $2.4 \pm 0.1 \%$ casein, and $4.1 \pm 0.1 \%$ lactose. The total calcium contents of the cream mixes were $102 \pm 6$ $\mathrm{mg} / 100 \mathrm{~g}$ of milk. Cream cheeses with similar chemical compositions were produced to avoid possible changes in texture and rheology due to any variation in composition (Table 2). No significant differences were observed between the concentrations of moisture, fat, protein, lactose, and lactic acid in the cream cheeses stabilized with the different stabilizers. The target composition of cream cheeses were close to the maximum moisture content of $55 \%$ and a minimum fat content of $33 \%$, according to the US standard of identity of cream cheese (Code of Federal Regulations, 2006).

\section{Rheological Properties of Cream Cheese}

The $\mathrm{G}^{\prime}$ values of the cream cheeses stabilized with XG, LBG, GG, and CBN were not significantly different at low temperatures $\left(<30^{\circ} \mathrm{C}\right)$ during the heating cycle of the temperature sweep tests (Figure 4a). At low temperatures, the protein matrix, and the mostly solid fat embedded in the matrix, were probably the dominant contributors to the $\mathrm{G}^{\prime}$ values of cream cheeses. During heating at higher temperatures (from 30 to $70^{\circ} \mathrm{C}$ ), XG- and CBN-stabilized cream cheeses exhibited higher $\mathrm{G}^{\prime}$ values than the cream cheeses stabilized with the galactomannans (LBG and GG). No significant differences were observed between the LBG- and GG-stabilized cream cheeses, or between those stabilized with the $\mathrm{CBN}$ and $\mathrm{XG}$ at any temperature during the heating cycle. The higher $\mathrm{G}^{\prime}$ values of $\mathrm{XG}$ and $\mathrm{CBN}$-stabilized cream cheeses could be because both stabilizer systems (XG and CBN) form gels in the aqueous phase of cream cheeses as observed in our model solutions. The presence of CBN gels in the aqueous phase of cream cheeses may reduce the mobility of the system, increase its structural stability to high temperatures and contribute to its overall stiffness.

During the cooling cycle, XG-stabilized cream cheeses tended to have higher $\mathrm{G}^{\prime}$ values than the cream cheeses stabilized with the galactomannans (LBG and GG; Figure 4b). The CBN-stabilized cream cheeses had significantly higher $G^{\prime}$ values than those stabilized with GG and LBG at temperatures below $65^{\circ} \mathrm{C}$ and had the significantly $(P<0.05)$ highest $\mathrm{G}^{\prime}$ values at temperatures below $8^{\circ} \mathrm{C}$. When comparing the cream cheeses stabilized with GG to those stabilized with LBG, no significant differences $(P>0.05)$ were observed at any temperature during the heating or cooling cycles.

All samples exhibited a LT peak at temperatures between 20 to $30^{\circ} \mathrm{C}$ during the heating cycle (Figure 5a). A weak second LT peak was observed at $\sim 60^{\circ} \mathrm{C}$ in some samples during the heating cycle (Figure 5a). Similar LT profiles were reported in full-fat commercial cream cheese by Brighenti et al. (2008). The CBNstabilized cream cheese had lower LT values from 35 to $65^{\circ} \mathrm{C}$ than in the GG and LBG-stabilized cream cheeses (Figure 5a). No significant differences were observed between CBN and XG-stabilized cream cheeses. During the cooling cycle, at temperatures that ranged from 50

Table 2. Composition ${ }^{1}$ of cream cheeses made with individual stabilizers $(0.33 \%)$ or a combination of all 3 stabilizers (total of $0.33 \% ; \mathrm{n}=3$ )

\begin{tabular}{lcccc}
\hline & \multicolumn{4}{c}{ Treatment $^{2}$} \\
\cline { 2 - 4 } Item & Xanthan & Locust bean & Guar & Combination \\
\hline Moisture (\%) & $55.41^{\mathrm{a}}$ & $55.61^{\mathrm{a}}$ & $55.98^{\mathrm{a}}$ & $54.99^{\mathrm{a}}$ \\
Fat (\%) & $33.06^{\mathrm{a}}$ & $32.74^{\mathrm{a}}$ & $33.26^{\mathrm{a}}$ & $33.33^{\mathrm{a}}$ \\
Salt (\%) & $0.90^{\mathrm{a}}$ & $0.82^{\mathrm{b}}$ & $0.87^{\mathrm{ab}}$ & $0.83^{\mathrm{ab}}$ \\
Protein (\%) & $7.30^{\mathrm{a}}$ & $7.19^{\mathrm{a}}$ & $7.13^{\mathrm{a}}$ & $7.23^{\mathrm{a}}$ \\
Lactose (\%) & $2.41^{\mathrm{a}}$ & $2.33^{\mathrm{a}}$ & $2.40^{\mathrm{a}}$ & $2.33^{\mathrm{a}}$ \\
Lactic acid (\%) & $0.35^{\mathrm{a}}$ & $0.34^{\mathrm{a}}$ & $0.34^{\mathrm{a}}$ & $0.31^{\mathrm{a}}$ \\
pH & $4.93^{\mathrm{b}}$ & $5.02^{\mathrm{a}}$ & $5.02^{\mathrm{a}}$ & $5.05^{\mathrm{a}}$ \\
\hline
\end{tabular}

${ }_{\mathrm{a}, \mathrm{b}}$ Means within a row with different superscripts differ $(P<0.05)$.

${ }^{1}$ Mean of triplicate experiments.

${ }^{2}$ Xanthan $=$ cream cheese manufactured with $0.33 \%$ xanthan gum as a stabilizer; locust bean $=$ cream cheese manufactured with $0.33 \%$ locust bean gum as a stabilizer; guar = cream cheese manufactured with $0.33 \%$ guar gum as a stabilizer; and combination $=$ cream cheese manufactured with a combination (total $=0.33 \%$ ) of $0.11 \%$ xanthan gum, $0.11 \%$ locust bean, and $0.11 \%$ guar gum as a stabilizer. 


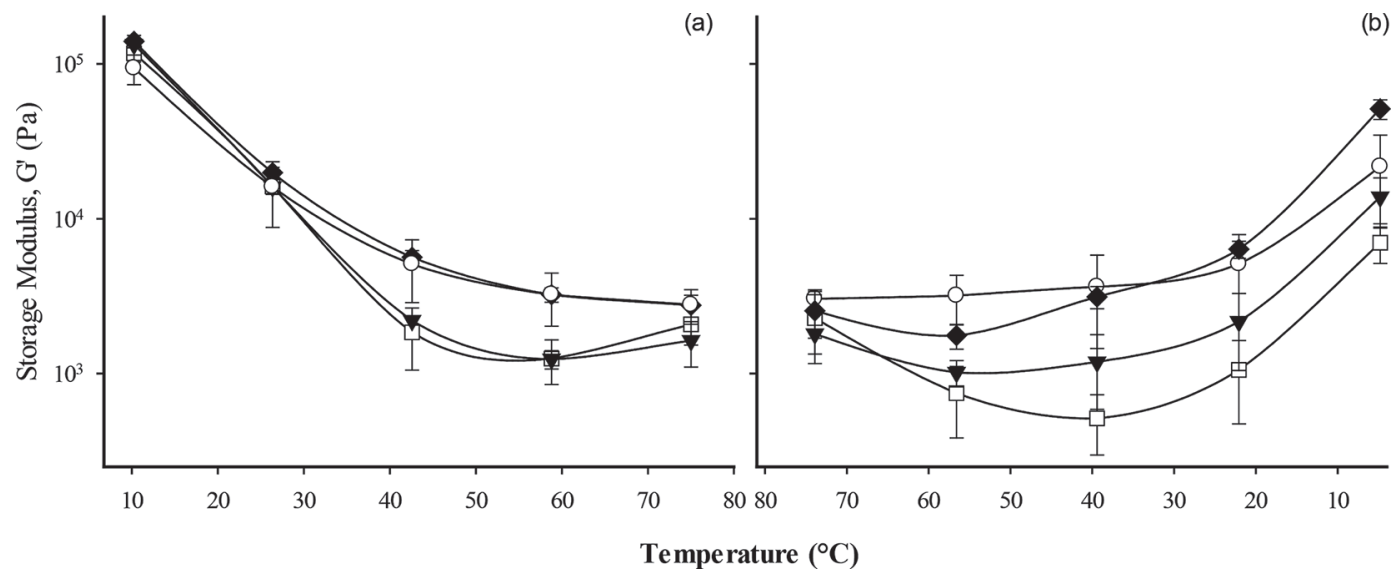

(b)

Figure 4. Storage modulus values of cream cheeses made with xanthan gum (O), locust bean gum ( $\square$ ), guar gum ( $\mathbf{v})$, and a combination
all 3 stabilizers (xanthan, locust bean gum, and guar gum; ) during heating (a) and cooling (b). Heating was from 5 to $80^{\circ} \mathrm{C}$ and cooling from 80 to $5^{\circ} \mathrm{C}$ at $1^{\circ} \mathrm{C} / \mathrm{min}$. Total concentration of stabilizer $(0.33 \%)$ was the same in all cream cheeses; the combination contained $0.11 \%$ of each stabilizer. Values are means of 3 replicates and error bars represent SD of the mean.

to $15^{\circ} \mathrm{C}$, the $\mathrm{LT}$ values of the $\mathrm{CBN}$-stabilized cream cheeses were lower than those of the cream cheeses made with the individual stabilizers. The LT values of CBN-stabilized cream cheeses at different temperature regions of the heating and cooling cycles were significantly lower than the LT values of the cream cheeses made with the individual stabilizers (Figures 5a and b). This is in agreement with the LT values obtained for the CBN solutions, which were significantly $(P<0.05)$ lower than the values obtained for the individual solutions of XG, LBG, and GG at all temperatures of the heating and cooling cycles (Figures $3 \mathrm{a}$ and b). However, the magnitude of the differences between the LT values of the various types of cream cheeses was small. In all cases, LT values were relatively low (i.e., <0.40), which indicate that throughout the heating cycle, cream cheese structure remained solid-like. Low LT values of cream cheese during heating are characteristic for this type of cheese (Brighenti et al., 2008, 2018), and are likely due to its low pH (Johnson and Lucey, 2006). No significant $(P>0.05)$ differences were observed in the LT values between cream cheeses stabilized with the individual stabilizers (XG-, GG-, or LBG-stabilized cream cheeses) at any temperature during the heating or cooling cycles.

\section{Instrumental Texture and Sensory Properties of Cream Cheeses}

The textural results from both instrumental and sensory analyses indicate that the cream cheeses stabilized with the individual stabilizers were not sig-

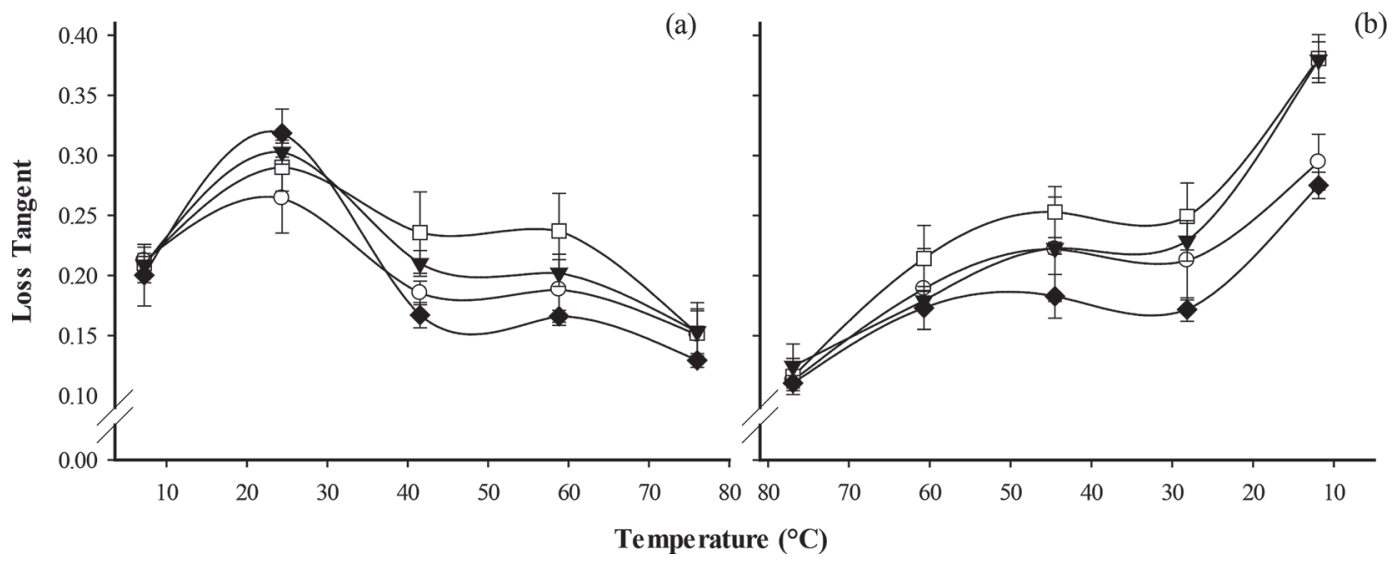

Figure 5. Loss tangent values of cream cheeses made with xanthan gum $(\bigcirc)$, locust bean gum $(\square)$, guar gum ( $\mathbf{\nabla})$, and a combination of all 3 stabilizers (xanthan, locust bean gum, and guar gum; $\downarrow$ ) during heating (a) and cooling (b). Heating was from 5 to $80^{\circ} \mathrm{C}$ and cooling from 80 to $5^{\circ} \mathrm{C}$ at $1^{\circ} \mathrm{C} / \mathrm{min}$. Values are means of 3 replicates and error bars represent $\mathrm{SD}$ of the mean. Total concentration of stabilizer $(0.33 \%)$ was the same in all cream cheeses; the combination contained $0.11 \%$ of each stabilizer. 
Table 3. Instrumental textural (determined by texture profile analysis; TPA) and sensory properties ${ }^{1}$ of cream cheeses manufactured with different stabilizers as evaluated by trained sensory panelists after storage for 1 mo at $4^{\circ} \mathrm{C}(\mathrm{n}=3)$

\begin{tabular}{lcccc}
\hline & \multicolumn{4}{c}{ Treatment $^{2}$} \\
\cline { 2 - 5 } Item & Xanthan & Locust bean & Guar & Combination \\
\hline TPA hardness $^{3}(\mathrm{~N})$ & $7.4^{\mathrm{a}}$ & $8.7^{\mathrm{a}}$ & $7.7^{\mathrm{a}}$ & $11.3^{\mathrm{b}}$ \\
Sensory attribute $^{\mathrm{a}}$ & & & & \\
Firmness & $10.2^{\mathrm{b}}$ & $10.9^{\mathrm{b}}$ & $10.7^{\mathrm{b}}$ & $12.0^{\mathrm{a}}$ \\
Stickiness & $6.7^{\mathrm{a}}$ & $6.6^{\mathrm{a}}$ & $7.1^{\mathrm{a}}$ & $5.0^{\mathrm{b}}$ \\
Gumminess & $6.5^{\mathrm{b}}$ & $6.6^{\mathrm{b}}$ & $6.3^{\mathrm{b}}$ & $7.3^{\mathrm{a}}$ \\
Cohesiveness of mass & $11.0^{\mathrm{b}}$ & $11.2^{\mathrm{b}}$ & $11.3^{\mathrm{b}}$ & $12.7^{\mathrm{a}}$ \\
Difficulty to dissolve & $10.6^{\mathrm{b}}$ & $10.7^{\mathrm{b}}$ & $10.7^{\mathrm{b}}$ & $11.6^{\mathrm{a}}$ \\
Difficulty to spread & $8.9^{\mathrm{b}}$ & $9.4^{\mathrm{b}}$ & $9.4^{\mathrm{b}}$ & $10.6^{\mathrm{a}}$ \\
\hline
\end{tabular}

a,b Means within a row with different superscripts differ $(P<0.05)$.

${ }^{1}$ Mean of triplicate experiments.

${ }^{2}$ Xanthan $=$ cream cheese manufactured with $0.33 \%$ xanthan gum as a stabilizer; locust bean $=$ cream cheese manufactured with $0.33 \%$ locust bean gum as a stabilizer; guar = cream cheese manufactured with $0.33 \%$ guar gum as a stabilizer; and combination $=$ cream cheese manufactured with a combination (total $=0.33 \%$ ) of $0.11 \%$ xanthan gum, $0.11 \%$ locust bean, and $0.11 \%$ guar gum as a stabilizer.

${ }^{3}$ Hardness was measured by texture analyzer.

${ }^{4}$ The numerical intensity scale for each attribute ranged from 0 to 15 ; higher numbers indicate higher intensities.

nificantly $(P>0.05)$ different from each other (Table $3)$. However, the CBN-stabilized cream cheeses had a firmer texture than the cream cheeses made with the individual stabilizers as evidenced by higher values of hardness determined by texture profile analysis, and sensory attributes such as firmness, cohesiveness of mass, difficulty to dissolve, gumminess, and difficulty to spread (Table 3). At low temperatures $\left(<40^{\circ} \mathrm{C}\right)$ the small deformation properties did not significantly differ between all samples (Figure 4), in contrast to the textural differences observed between cheeses stabilized by CBN and the other stabilizers (Table 3). Texture and sensory analysis are large deformation tests where yielding/fracture behavior are involved, which are in contrast to nondestructive rheological methods. In a previous study (Brighenti et al., 2008), we found that in cream cheese, the sensory parameters firmness, cohesiveness of mass, difficulty to dissolve, gumminess, and difficulty to spread were strongly correlated and associated with the hardness of the product. No significant $(P>0.05)$ differences were perceived in the particle sizes of the different cream cheeses (results not shown).

The CBN-stabilized cream cheeses were also found to be less sticky than the cream cheeses made with the individual stabilizers. A decrease in stickiness values with an increase in elasticity of a material is in accordance with the Dahlquist criterion (Dahlquist, 1969). The firmer structure of the CBN-stabilized cream cheeses was probably due to the presence of a CBN gel in the aqueous phase that helped to provide additional structural rigidity in contrast to the systems formed by the individual stabilizers. The CBN-stabilization probably made a greater contribution to the firmness of cream cheese than the weak gels formed by XG, or the viscous solutions formed by GG or LBG within the aqueous phase of cream cheese.

Several studies have indicated that addition of XG to skim milk results in phase separation at the natural milk pH (i.e., $\mathrm{pH} \sim 6.6$; Hemar et al., 2001; Aichinger et al., 2007). In cream cheese, stabilizers are added after the formation of the acid-induced gel, when caseins are close to their isoelectric point. At this $\mathrm{pH}(\sim 4.6)$ selfassociation of caseins is strongest and incompatibility between caseins and XG is likely increased (Syrbe et al., 1998). However, in cream cheese it is unlikely that any incompatibility leads to an overall phase separation, as the protein is already a gel matrix as well as the high viscosity of the continuous phase prevents the coalescence of the dispersed phase where the stabilizers are located (Bot and Vervoot, 2006). However, more studies should be conducted to better understand the location and types of molecular interactions between stabilizers and caseins in the cream cheese system.

\section{CONCLUSIONS}

The type of stabilizer used to make cream cheese had an effect on its texture and thermal behavior. The use of an acidified model system helped to clarify the effect of added stabilizers in the cream cheese system. Distinct differences were observed between the rheological properties of individual stabilizer solutions (XG, GG, or LBG) and the CBN of all 3 stabilizers. The CBN solution formed a strong, thermally reversible gel, the 
xanthan solution formed a weak gel that was not greatly affected by temperature, and the individual solutions of galactomannans behaved as entangled polymer solutions at all temperatures in the range from 5 to $80^{\circ} \mathrm{C}$. It is possible that the presence of a stabilizer gel network in the aqueous phase of the XG- and CBN-stabilized cheeses helped maintain the structure of the system at high temperatures. The rheological behaviors of the different stabilizers in solution were similar to the behavior observed in the cream cheeses manufactured with these stabilizers. The cream cheese made with a CBN of the 3 stabilizers had the highest stiffness and hardness values due to the synergistic interaction between $\mathrm{XG}$ and galactomannans that resulted in gelation of this stabilizer blend within the aqueous phase of the cheese. Selection of an individual stabilizer or a CBN could be used to alter the texture and sensory properties of cream cheese. For example, compared with a CBN of stabilizers, the use of XG alone as a stabilizer produced softer and stickier cream cheese that was also easier to spread.

\section{ACKNOWLEDGMENTS}

The authors thank the Center for Dairy Research personnel for their assistance and support in milk processing, cheesemaking, sensory, and analytical work. We also thank DSM Food Specialties USA (Milwaukee, WI) and Cargill Inc. (Minneapolis, MN), respectively, for their donations of starter cultures and the different stabilizers used in this study. The financial support of the Dairy Farmers of Wisconsin (Madison, WI), and National Dairy Council (Rosemont, IL) is greatly appreciated. The authors have not stated any conflicts of interest.

\section{REFERENCES}

Aichinger, P. A., M. L. Dillmann, S. Rami-Shojaei, A. Paterson, M. Michel, and D. S. Horne. 2007. Xanthan gum in skim milk: Designing structure into acid milk gels. Pages 289-302 in Food Colloids, Self-Assembly and Material Science. E. Dickinson and M. E. Leser, ed. The Royal Society of Chemistry, Cambridge, UK.

AOAC International. 2000. Official Methods of Analysis. Vol. 1. 17th ed. AOAC International, Arlington, VA.

Bot, A., and S. Vervoort. 2006. Hydrocolloid functionality in spreads and related products. Pages 381-394 in Gums and Stabilisers for the Food Industry No. 13. P. A. Williams and G. O. Phillips, ed. The Royal Society of Chemistry, Cambridge, UK.

Brighenti, M., S. Govindasamy-Lucey, J. J. Jaeggi, M. E. Johnson, and J. A. Lucey. 2018. Effects of processing conditions on the texture and rheological properties of model acid gels and cream cheese. J. Dairy Sci. 101:6762-6775. https://doi.org/10.3168/jds.2018-14391.

Brighenti, M., S. Govindasamy-Lucey, K. Lim, K. Nelson, and J. A. Lucey. 2008. Characterization of the rheological, textural and sensory properties of samples of commercial US cream cheese that had different fat contents. J. Dairy Sci. 91:4501-4517. https://doi.org/ 10.3168/jds.2008-1322.
Code of Federal Regulations. 2006. Food and Drugs: CFR Part 133 Cheese and Related Cheese Products. Department of Health and Human Services, Washington, DC. Accessed Aug. 16, 2019. https: //www.accessdata.fda.gov/scripts/cdrh/cfdocs/cfcfr/CFRSearch $. \mathrm{cfm} ? \mathrm{fr}=133.133$.

Copetti, G., M. Grassi, R. Lapasin, and S. Pricl. 1997. Synergistic gelation of xanthan gum with locust bean gum: A rheological investigation. Glycoconj. J. 14:951-961. https://doi.org/10.1023/A: 1018523029030.

Dahlquist, C. A. 1969. Pressure-sensitive adhesives. Pages 219-260 in Treatise on Adhesion and Adhesives. Vol. 2. R. L. Patrick, ed. Marcel Dekker, New York, NY.

Daubert, C. R., and E. A. Foegeding. 1998. Rheological properties for food analysis. Pages 551-569 in Food Analysis. 2nd ed. S. S. Nielsen, ed. Aspen Publishers Inc., Gaithersburg, MD.

Dea, I. C. M. 1990. Structure/function relationships of galactomannans and food grade cellulosics. Pages 373-382 in Gums and Stabilisers for the Food Industry-No. 5. G. O. Phillips, D. J. Wedlock, and P. A. Williams, ed. Oxford University Press Ltd., Oxford, UK.

Everett, D. W., and R. E. McLeod. 2005. Interactions of polysaccharide stabilisers with casein aggregates in stirred skim-milk yoghurt. Int. Dairy J. 15:1175-1183. https://doi.org/10.1016/j.idairyj.2004 .12 .004 .

Fernandes, P. B. 1995. Influence of galactomannan on the structure and thermal behaviour of xanthan/galactomannan mixtures. J. Food Eng. 24:269-283. https://doi.org/10.1016/0260-8774(94)P2647-N.

Fox, P. F., T. P. Guinee, T. M. Cogan, and P. L. H. McSweeney. 2000. Fresh acid-curd cheese varieties. Pages $363-387$ in Fundamentals of Cheese Science. P. F. Fox, T. P. Guinee, T. M. Cogan, and P. L. H. McSweeney, ed. Aspen Publ., Gaithersburg, MD.

Gigante, M. L., M. Almena-Aliste, and P. S. Kindstedt. 2006. Effect of cheese $\mathrm{pH}$ and temperature on serum phase characteristics of cream cheese during storage. J. Food Sci. 71:C7-C11. https://doi .org/10.1111/j.1365-2621.2006.tb12390.x.

Govindasamy-Lucey, S., J. J. Jaeggi, M. E. Johnson, T. Wang, and J. A. Lucey. 2007. Use of cold microfiltration retentates produced by polymeric membranes for standardization of milks for manufacture of pizza cheese. J. Dairy Sci. 90:4552-4568. https://doi.org/ 10.3168/jds.2007-0128.

Guinee, T. P., P. D. Pudja, and N. Y. Farkye. 1993. Fresh acid-curd cheese varieties. Pages 363-419 in Cheese: Chemistry, Physics and Microbiology. Vol. 2: Major Cheese Groups. 2nd ed. P. F. Fox, ed. Chapman \& Hall, London, UK.

Hemar, Y., M. Tamehana, P. A. Munro, and H. Singh. 2001. Viscosity, microstructure and phase behaviour of aqueous mixtures of commercial milk protein products and xanthan gum. Food Hydrocoll. 15:565-574. https://doi.org/10.1016/S0268-005X(01)00077-7.

Hunt, C. C., and J. R. Maynes. 1997. Current issues in the stabilization of cultured dairy products. J. Dairy Sci. 80:2639-2643. https: //doi.org/10.3168/jds.S0022-0302(97)76221-0.

International Dairy Federation. 2004. Cheese and processed cheese products: Determination of the total solids content (reference method). IDF Standard 4. International Dairy Federation, Brussels, Belgium.

International Dairy Federation. 2010. Milk, cream and evaporated milk - Determination of total solids content (reference method). IDF Standard 21. International Dairy Federation, Brussels, Belgium.

Johnson, M. E., and J. A. Lucey. 2006. Calcium: A key factor in controlling cheese functionality. Aust. J. Dairy Technol. 61:147-153.

Khouryieh, H. A., T. J. Herald, F. Aramouni, and S. Alavi. 2007. Intrinsic viscosity and viscoelastic properties of xanthan/guar mixtures in dilute solutions: Effect of salt concentration on the polymer interactions. Food Res. Int. 40:883-893. https://doi.org/ 10.1016/j.foodres.2007.03.001.

Kitamura, S., T. Kuge, and B. T. Stokke. 1990. A differential scanning calorimetric study of the conformational transition of xanthan in aqueous NaCl. Pages 329-332 in Gums and Stabilisers for the Food Industry-5. G. O. Phillips, D. J. Wedlock, and P. A. Williams, ed. Oxford University Press Ltd., Oxford, UK. 
Kosikowski, F. V., and V. V. Mistry. 1997. Bakers', Neufchatel, cream, quark and ymer. Pages 147-161 in Cheese and Fermented Milk Foods. Vol. 1: Origins and Principles. 3rd ed. F. V. Kosikowski, and V. V. Mistry, ed. F. V. Kosikowski LLC, Westport, CT.

Lucey, J. A. 2002. Acid and acid/heat coagulated cheese. Pages 350356 in Encyclopedia of Dairy Sciences. H. Roginski, J. W. Fuquay, and P. F. Fox, ed. Academic Press, London, UK.

Lucey, J. A., C. T. Teo, P. A. Munro, and H. Singh. 1997. Rheological properties at small (dynamic) and large (yield) deformations of acid gels made from heated milk. J. Dairy Res. 64:591-600. https: //doi.org/10.1017/S0022029997002380.

Marshall, R. T. 1992. Standard methods for the examination of dairy products. 16th ed. American Public Health Association, Washington, DC.

Meilgaard, M. C., G. V. Civille, and B. T. Carr. 1999. Sensory Evaluation Techniques. 3rd ed. CRC Press, Boca Raton, FL.

Morris, V. J. 1990. Science, structure and applications of microbial polysaccharides. Pages 315-328 in Gums and Stabilisers for the Food Industry-5. G. O. Phillips, D. J. Wedlock, and P. A. Williams, ed. Oxford University Press Ltd., Oxford, UK.

Morris, V. J. 1995. Bacterial polysaccharides. Pages 341-375 in Food Polysaccharides and Their Applications. A. M. Stephen, ed. Marcel Dekker Inc., New York, NY.

Morris, V. J. 1998. Gelation of polysaccharides. Pages 143-226 in Functional Properties of Food Macromolecules. 2nd ed. S. E. Hill, D. A. Ledward, and J. R. Mitchell, ed. Aspen Publishers Inc. Gaithersburg, MD.

Muller, G., M. Aurhourrache, J. Lecourtier, and G. Chauveteau. 1986. Salt dependence of the conformation of a single-stranded xanthan. Int. J. Biol. Macromol. 8:167-172. https://doi.org/10.1016/0141 $-8130(86) 90021-8$

Pai, V. B., and S. A. Khan. 2002. Gelation and rheology of xanthan/ enzyme-modified guar blends. Carbohydr. Polym. 49:207-216 https://doi.org/10.1016/S0144-8617(01)00328-9.

Pelletier, E., C. Viebke, J. Meadows, and P. A. Williams. 2001. A rheological study of the order-disorder conformational transition of xanthan gum. Biopolymers 59:339-346. https://doi.org/10.1002/ 1097-0282(20011015)59:5<339::AID-BIP1031>3.0.CO:2-A.

Richardson, R. K., and S. B. Ross-Murphy. 1987a. Non-linear viscoelasticity of polysaccharide solutions. 1: Guar galactomannan solutions. Int. J. Biol. Macromol. 9:250-256. https://doi.org/10.1016/ 0141-8130(87)90062-6.
Richardson, R. K., and S. B. Ross-Murphy. 1987b. Non-linear viscoelasticity of polysaccharide solutions. 2: Xanthan polysaccharide solutions. Int. J. Biol. Macromol. 9:257-264. https://doi.org/10 1016/0141-8130(87)90063-8.

Robinson, G., S. B. Ross-Murphy, and E. R. Morris. 1982. Viscositymolecular weight relationships, intrinsic chain flexibility, and dynamic solution properties of guar galactomannan. Carbohydr. Res. 107:17-32. https://doi.org/10.1016/S0008-6215(00)80772-7.

Rochefort, W. E., and S. Middleman. 1987. Rheology of xanthan gum: Salt, temperature, and strain effects in oscillatory and steady shear experiments. J. Rheol. 31:337-369. https://doi.org/10.1122/ 1.549953.

Sanchez, C., R. Zuniga-Lopez, C. Schmitt, S. Despond, and J. Hardy 2000. Microstructure of acid-induced skim milk-locust bean gumxanthan gels. Int. Dairy J. 10:199-212. https://doi.org/10.1016/ S0958-6946(00)00030-3.

Schulz-Collins, D., and B. Senge. 2004. Acid and acid/rennet-curd cheeses. Part A: Quark, cream cheese and related varieties. Pages 301-328 in Cheese Chemistry, Physics and Microbiology. Vol. 2: Major Cheese Groups. 3rd ed. P. F. Fox, P. L. H. McSweeney, T. M. Cogan, and T. P. Guinee, ed. Elsevier Science \& Technology, London, UK.

Sittikijyothin, W., D. Torres, and M. P. Gonçalves. 2005. Modelling the rheological behaviour of galactomannan aqueous solutions. Carbohydr. Polym. 59:339-350. https://doi.org/10.1016/j.carbpol .2004.10.005.

Syrbe, A., W. J. Bauer, and H. Klostermeyer. 1998. Polymer science concepts in dairy systems - An overview of milk protein and food hydrocolloid interaction. Int. Dairy J. 8:179-193. https://doi.org/ 10.1016/S0958-6946(98)00041-7.

Williams, P. A., and G. O. Phillips. 1995. Interactions in mixed polysaccharides systems. Pages 463-500 in Food Polysaccharides and Their Applications. A. M. Stephen, ed. Marcel Dekker Inc., New York, NY.

\section{ORCIDS}

S. Govindasamy-Lucey ㄴ) https://orcid.org/0000-0001-9485-7416

M. E. Johnson ( https://orcid.org/0000-0003-2123-6787

J. A. Lucey (® https://orcid.org/0000-0002-8838-5130 